\title{
PERFIL E PERCEPÇÕES SOBRE A PRÁTICA PEDAGÓGICA DO PROFESSOR BACHAREL NA EDUCAÇÃO PROFISSIONAL
}

\author{
J. A. OLIVEIRA ${ }^{*}$, Y. F. O. SILVA \\ Universidade Estadual de Goiás \\ jamilleamorim@hotmail.com*
}

Submetido 24/02/2018 - Aceito 23/07/2018

DOI: $10.15628 /$ holos. 2018.6998

\begin{abstract}
RESUMO
O presente trabalho é um recorte da proposta de pesquisa de mestrado que discute as concepções de alguns professores bacharéis sobre suas práticas pedagógicas e analisa se nessas práticas docentes contemplam os elementos e os conceitos da abordagem sociocultural de Vygotsky. A pesquisa está fundamentada pelos estudos de Veiga (1992) para tratar sobre a prática pedagógica, e pelas contribuições de Vygotsky (2007), Masetto (2000), Figueiredo (2006) ao contemplar os conceitos centrais de Zona de Desenvolvimento Proximal (ZDP), Mediação e Aprendizagem Colaborativa, entre outros. A metodologia utilizada é de abordagem qualitativa, tendo a entrevista semiestruturada como instrumento de coleta de dados. Os sujeitos investigados são quatro
\end{abstract}

professores de um Câmpus da Rede Federal de Ensino do Estado de Goiás que atuam na Educação Profissional Básica. Os resultados da pesquisa evidenciam que apesar da predominância de uma prática pedagógica repetitiva desenvolvida por esses professores, há, também, a presença dos elementos/conceitos da abordagem sociocultural de Vygotsky em algumas situações nas aulas desses professores bacharéis contemplando a interação social com atividades colaborativas, uso dos scaffoldings, propiciando assim, a execução da ZPD do aluno. Todavia, os elementos da teoria sociocultural externados por esses professores é algo aleatório desenvolvido por eles, sem objetivos pedagógicos preestabelecidos, baseados apenas nas suas próprias bagagens culturais.

PALAVRAS-CHAVE: Prática Pedagógica, Professor Bacharel, Educação Profissional, Abordagem sociocultural.

\section{PROFILE AND PERCEPTIONS ON THE PEDAGOGICAL PRACTICE OF BACHAREL TEACHER IN PROFESSIONAL EDUCATION}

\begin{abstract}
The present work is part of the proposal of masters research that discusses the conceptions of some bachelor teachers on their pedagogical practices and analyzes if in these practices teachers contemplate the elements and the concepts of the sociocultural approach of Vygotsky. The research is based on studies by Veiga (1992) to deal with pedagogical practice, and by the contributions of Vygotsky (2007), Masetto (2000), Figueiredo (2006) to contemplate the central concepts of Zone Proximal Development (ZPD) Mediation and Collaborative Learning, among others. The methodology used is a qualitative approach, with the semi-structured interview as a data collection instrument. The subjects investigated are four teachers from a Campus of the Federal Institute of Education of the State of Goiás who work in Basic Professional Education. The results of the research show that despite the predominance of a repetitive pedagogical practice developed by these
\end{abstract}

teachers, there is also the presence of elements / concepts of the sociocultural approach of Vygotsky in some situations in the classes of these bachelors teachers contemplating the social interaction with collaborative activities, use of the scaffoldings, thus providing the execution of the student's ZPD. However, the elements of sociocultural theory expressed by these teachers are something randomly developed by them, without pre-established pedagogical objectives, based only on their own cultural baggage. 
KEYWORDS: Pedagogical Practice. Bachelor Teachers. Professional Education. Sociocultural Approach.

\section{INTRODUÇÃO}

A prática pedagógica do professor é considerada como as atividades rotineiras desenvolvidas na sala de aula. Uma prática pedagógica com base na teoria sociocultural contempla os conceitos centrais de Zona de Desenvolvimento Próximal (ZDP) e Mediação, o que pressupõe uma aprendizagem colaborativa em que os alunos possam interagir uns com os outros e desenvolver o espírito crítico e sua autonomia para a construção do conhecimento. O contrário disso, pode significar uma prática sem referências pedagógicas ou até mesmo com referências pedagógicas, mas de forma isolada e/ou fragmentada. Consequentemente, o exercício da docência poderá ter prejuízos em seu processo de ensino e aprendizagem.

A Educação Profissional e Tecnológica (EPT) tem se ampliado e seus docentes por serem das áreas técnicas, sendo que estas, em sua maioria, não contemplam as discussões relativas aos processos educativos, ainda que esses professores adotem e desenvolvam na sua sala de aula uma prática pedagógica.

A formação para a docência na EPT não vem explicitamente delimitada na Lei de Diretrizes e Bases (Lei no 9.394/1996). Contudo, a Resolução no 1, de 27 de março de $2008^{1}$ elenca no seu artigo 4으, que a formação para os professores da EPT deve ser docentes:

I - habilitados em cursos de licenciatura plena e em Programas Especiais de Formação Pedagógica de Docentes;

II - pós-graduados em cursos de especialização para formação de docentes para a Educação Profissional Técnica de Nível Médio, estruturados por área de habilitação profissional;

III - graduados bacharéis e tecnólogos com diploma de Mestrado ou Doutorado na área do componente curricular da Educação Profissional Técnica de Nível médio. (BRASIL 2008).

A letra da lei expõe claramente que a pós-graduação stricto sensu se configura como uma exigência para a atuação do bacharel ou tecnólogo como professor de Educação Profissional tecnológica. Todavia, a citada Resolução, no seu artigo 7으 abre a possibilidade dos bacharéis e tecnólogos integrarem o magistério da educação básica sem preencherem os requisitos elencados acima:

Art. 70 Excepcionalmente, podem ser considerados docentes integrantes do magistério da Educação Básica, para efeito da destinação de recursos nos termos do artigo 22 da Lei no11.494/2007:

III - no Ensino Médio integrado com a Educação Profissional Técnica de nível médio:

a) os graduados bacharéis e tecnólogos que, na falta de licenciados, recebem autorização do órgão competente de cada sistema, em caráter precário e

\footnotetext{
${ }^{1}$ A Resolução no 1, de 27 de março de 2008 define os profissionais do magistério, para efeitos da aplicação do artigo 22, da Lei no 11.494/2007.
} 
provisório, para exercer a docência e aos quais se proporcione formação pedagógica em serviço;

E amparados por essa regulamentação é que a maioria dos concursos docentes, especialmente nos Institutos Federais, acontece, resultando assim em docentes das áreas técnicas, atuantes na educação básica profissional, oriundos de graduações diversas do bacharelado que não contemplam as discussões relativas aos processos educativos. Dessa forma, como não há licenciados nas áreas técnicas de maneira a atender a atual demanda da expansão da modalidade, as vagas são preenchidas, legalmente, por profissionais que não receberam formação para a docência, ou seja, formação para a área da educação no que tange a disciplinas pedagógicas e conhecimentos didáticos contemplando conhecimentos de metodologia de ensino, práticas pedagógicas, reflexões sobre o saber docente, ou seja, conhecimentos para pensar a profissão de professor.

$\mathrm{Na}$ verdade, o único momento que os conhecimentos pedagógicos/metodológicos dos candidatos a professores da EPT nos Institutos Federais poderiam ser aferidos seria no momento de seu processo seletivo em sua aula prática, que é uma das modalidades de avaliação/seleção previstas nos editais de concurso para docente. Contudo, percebemos que este espaço, geralmente limitado a cinquenta minutos, se configura como insuficiente para verificar os conhecimentos dos futuros docentes sobre a relação de ensino e aprendizagem.

Diante disso, faltam aos professores bacharéis a fundamentação teórica e prática para desenvolver uma prática pedagógica que contemple o conhecimento do currículo, do processo avaliativo, das metodologias e demais elementos que fazem parte do conjunto de ações e saberes pedagógicos característicos da profissão docente.

Nesse sentido, discutiremos nesse artigo as concepções de alguns professores bacharéis atuantes em um Câmpus do Instituto Federal de Goiás (IFG) sobre suas práticas pedagógicas e analisaremos se em suas práticas docentes contemplam os elementos e os conceitos da abordagem sociocultural de Vygotsky.

Esta é uma investigação de abordagem qualitativa e usaremos como instrumento de coleta de dados a entrevista semiestruturada a fim de explorar as respostas e formular discussões a partir dos dados obtidos, nos permitindo chegar a conclusões baseadas em evidências.

Este artigo está dividido em quatro partes: primeiro relacionamos a prática pedagógica e a abordagem sociocultural de Vygotsky na atividade docente; em seguida explicamos como se deram as escolhas metodológicas adotadas; traçaremos o perfil dos docentes da educação profissional que colaboraram com a pesquisa, bem como apontaremos seus olhares e percepções sobre a suas práticas pedagógicas de acordo com algumas categorias elencadas, e por último apresentaremos as considerações finais sobre as constatações e concepções dos docentes nesse perfil pesquisado. 


\section{EPT E A PRÁTICA PEDAGÓGICA}

A Rede Federal de Educação Profissional teve seu marco regulatório traçado no ano de 1909, pelo Decreto no 7.566, do Presidente Nilo Peçanha. Como resposta aos desafios de ordem econômica e política, "Nilo Peçanha instaurou uma rede de 19 Escolas de Aprendizes Artífices, dando origem à rede federal que culminou nas Escolas Técnicas e, posteriormente, nos CEFETs" (MANFREDI, 2002, p. 85).

Em 29 de dezembro de 2008, o presidente Luiz Inácio Lula da Silva sancionou a Lei no 11.892/08, que criou 38 Institutos Federais de Educação, Ciência e Tecnologia (IFET). De acordo com o Ministério da Educação, o modelo dos Institutos Federais ${ }^{2}$ surge como uma autarquia em regime especial de base educacional humanística-técnico-científica. Essa lei dispõe que os institutos deverão ter forte inserção na área de pesquisa e extensão, visando estimular o desenvolvimento de soluções técnicas e tecnológicas e estendendo seus benefícios à comunidade (BRASIL, online 2017). Não obstante, em se tratando da Educação Profissional, a maioria das áreas não são contempladas por cursos de licenciatura no Brasil. Com isso, são admitidos bacharéis para o exercício da docência, como condição inevitável para suprir as demandas de profissionais. Assim, os cursos ofertados com suas respectivas disciplinas, em considerável medida, são ministrados por profissionais de áreas específicas do conhecimento pautadas na tradição do bacharelado. Souza e Nascimento $(2013$, p. 416) afirma que "a falta de uma fundamentação teórica e prática que oriente o exercício da docência traz certos entraves e dificuldades para os bacharéis professores no seu desenvolvimento na profissão docente", uma vez que as chamadas disciplinas pedagógicas e conhecimentos didáticos não foram inseridos na graduação desses docentes.

Quando falamos da atuação de professores sem formação pedagógica inicial para atuação na EPT há, além da não obrigatoriedade legal de ser ter uma formação continuada pedagógica para atuarem na sala de aula, algumas crenças de que basta conhecer o conteúdo da disciplina para ser professor, bem como, o mito de que ensinar é apenas uma questão de talento ou que ensinar se aprende na prática, com acertos e erros. Contudo sabemos que a atividade docente não se limita a essas práticas propagadas pelo senso comum. O desempenho da docência também requer o uso de práticas.

Perrenoud (1993) pontua que a prática pedagógica do docente não é uma mera concretização de receitas, modelos didáticos ou esquemas conscientes de ação. Na visão de Veiga (1992, p. 16), a prática pedagógica é "uma prática social orientada por objetivos, finalidades e conhecimentos, e inserida no contexto da prática social. É uma dimensão da prática social que pressupõe a relação teoria-prática".

Já os Parâmetros Curriculares Nacionais (PCNs) trazem a visão do professor como mediador da aprendizagem e não expositor de conteúdos e o aluno um construtor do seu conhecimento e conhecedor das novas tecnologias bem como saber utilizá-las para sua prática (BRASIL, 2012). Essa concepção pressupõe, para o currículo do ensino tecnológico, a prática de educadores imbuídos de um verdadeiro espírito crítico, abertos à cooperação e o intercâmbio

\footnotetext{
${ }^{2}$ Previsto na Lei $11.892 / 2008$.
} 
entre as diferentes formas de ensino, num processo de autoformação, de reelaboração dos saberes inicial em confronto com sua prática vivenciada (BRASIL, 2012).

Nesse sentido, sugerimos a abordagem sociocultural de Vygotsky para nortear a prática pedagógica desses professores bacharéis. A teoria sociocultural tem como pressuposto que as atividades humanas e o seu desenvolvimento cognitivo seja produzido pelo processo de internalização da interação social em contextos culturais, sendo mediadas pela linguagem ou outros sistemas simbólicos podendo ser mais bem compreendidas quando investigadas no seu desenvolvimento histórico. Dessa forma, "o sujeito não é apenas ativo, mas interativo, porque forma conhecimento e se constitui a partir de relações intra e interpessoais" (OLIVEIRA, 2010).

Com isso, podemos inferir que a teoria sociocultural embasa a aprendizagem colaborativa. Nessa prática pedagógica os estudantes trabalham em pequenos grupos para atingir um determinado objetivo (FIGUEIREDO, 2006). Essa abordagem faz com que os alunos ensinem uns aos outros, fazendo com que o sucesso de um seja o sucesso do grupo. Ao trocarem conhecimento durante as interações em grupos, os estudantes não apenas obtêm um interesse maior na tarefa como também desenvolvem espírito crítico e reflexivo, sendo responsáveis pelo seu próprio aprendizado.

Além da aprendizagem colaborativa, a teoria sociocultural nos remete a dois conceitos centrais da teoria de Vygotsky, entendidos como aqueles que mais podem respaldar a prática pedagógica do professor. São eles a Zona de Desenvolvimento Próximo (ZDP) e a Mediação.

Vygostky (2007) distingue dois níveis de desenvolvimento da criança, o que também podemos considerar, em analogia, no processo de aprendizagem e desenvolvimento do aluno na fase adulta. O primeiro caracteriza-se pela habilidade da criança em realizar certas tarefas independentemente de outras pessoas. Já o segundo, é caracterizado pelas funções que essa criança pode desempenhar com a ajuda de outra pessoa. Portanto, a distância entre o que a criança aprende espontaneamente (nível de desenvolvimento real) e aquilo que ela realiza com o auxílio do meio (nível de desenvolvimento potencial) caracteriza o que denominamos de Zona de Desenvolvimento Proximal (ZDP).

A distância entre o nível de desenvolvimento real, em que se costuma determinar através da solução independente de problemas, e o nível de desenvolvimento potencial, determinado através da solução de problemas sob a orientação de um adulto ou em colaboração com companheiros mais capazes. (VYGOTSKY, 2007, p. 97)

A mediação é outro conceito central da teoria de Vygotsky que pode respaldar a prática pedagógica do professor. Entendemos como mediação o relacionamento entre professor-aluno na busca da aprendizagem como processo de construção de conhecimento, a partir da reflexão crítica das experiências e do processo de trabalho. De acordo com a teoria sociocultural Masetto (2000, p. 142), descreve habilidades do docente quanto à mediação do processo de ensino e aprendizagem:

O professor, embora, vez por outra, ainda desempenhe o papel do especialista que possui conhecimentos e/ou experiências a comunicar, na 
maioria das vezes desempenhará o papel de orientador das atividades do aluno, de consultor, facilitador da aprendizagem, desempenhará o papel de quem trabalha em equipe, junto com o aluno, buscando os mesmos objetivos; numa palavra, desenvolverá o papel de mediação pedagógica.

Nesse sentido, é possível compreender que, em colaboração, os sujeitos passam a fazer mais do que poderiam fazer sozinhos. Portanto, compartilhamos dos conhecimentos de Vygotsky (2007), e Masetto (2000) e entendemos que, por meio da mediação pedagógica, a atuação do professor, que deixa de ser um transmissor de conhecimentos e passa a ser um orientador de seus alunos no seu progresso intelectual. Daí a importância de implementações das teorias socioculturais de Vygotsky como práticas pedagógicas nas aulas desses professores bacharéis.

\section{METODOLOGIA}

Esta é uma investigação de abordagem qualitativa em que se preocupa em retratar a perspectiva dos participantes. Como bem destacam Ludke e André (1986), a pesquisa qualitativa tem o contato direto do pesquisador com a sua fonte direta de dados, que no nosso caso são os professores atuantes na Educação Profissional Básica de um Instituto Federal do Estado de Goiás.

Como instrumentos de coleta de dados, foi utilizada a entrevista semiestruturada para detalhar as narrativas dos professores sobre o objeto em estudo. Para a coleta de dados foram entrevistados quatro professores bacharéis de um Câmpus do IFG que atuam na EP Básica, dentre eles, dois professores que já possuem experiência de sala de aula e outros dois professores que iniciaram a carreira docente no começo desse ano. Como bem pontuam Ludke e André (1986), a entrevista favorece a captação imediata e corrente da informação desejada, permitindo inclusive o aprofundamento de pontos levantados por outras técnicas de coleta de análise mais superficial. Para tanto, a entrevista realizada foi organizada em duas categorias: o perfil desses docentes (identificação pessoal, formação acadêmica, titulação e experiência profissional) e o olhar desses docentes sobre suas práticas pedagógicas.

\subsection{Identificação pessoal: formação acadêmica, titulação e experiência profissional}

Nosso corpus de análise é constituído por quatro professores bacharéis, sendo três professores efetivos e um professor substituto. Quanto à formação acadêmica, três deles são formados em Engenharia Mecânica e um outro é formado em Engenharia Elétrica. Quanto à titulação, dois professores bacharéis possuem o mestrado concluído, sendo que um deles está com o doutorado em andamento. Um outro professor bacharel está com o mestrado trancado por indisponibilidade de tempo para cursar o mesmo, visto que para assumir o cargo de professor no IFG teve que mudar de cidade e o deslocamento dificultou a permanência no programa durante esse período e o outro está com o mestrado em andamento, caminhando para a conclusão. No quesito experiência profissional, dois dos professores entrevistados já possuem experiência em sala de aula e atuam na Rede Federal de Ensino. Um atua desde 2009 e o outro 
desde 2015. Os outros dois tiveram a primeira experiência docente no início de 2017. Tais informações podem ser melhores visualizadas por meio da tabela a seguir:

Tabela 1: Identificação pessoal: formação acadêmica, titulação e experiência profissional

\begin{tabular}{clllc}
\hline $\begin{array}{c}\text { DOCENTE } \\
\text { BACHAREL }\end{array}$ & VÍNCULO & FORMAÇÃO ACADÊMICA & TITULAÇÃO & $\begin{array}{c}\text { EXPERIÊNCIA } \\
\text { PROFISSIONAL NO } \\
\text { IFG }\end{array}$ \\
\hline 1 & Efetivo & Engenharia Mecânica & Mestrado & Desde 2009 \\
2 & Efetivo & Engenharia Elétrica & Mestrado em andamento & Desde 2015 \\
3 & Efetivo & Engenharia Mecânica & Mestrado em andamento & Desde 2017 \\
4 & Substituto & Engenharia Mecânica & Mestrado com Doutorado & Desde 2017 \\
\hline
\end{tabular}

Fonte: Tabela 1 - Elaboração da autora

\section{CONCEPÇÕES DOS PROFESSORES BACHARÉIS ATUANTES NA EPT SOBRE PRÁTICAS PEDAGÓGICAS}

\subsection{O olhar dos professores bacharéis sobre a prática pedagógica}

A prática pedagógica é entendida como uma ação do professor no espaço de sala de aula. É "[...] toda a bagagem cultural consolidada acerca da atividade educativa" (GIMENO SACRISTÁN, 1999, p.74). O primeiro questionamento feito aos professores bacharéis foi sobre como é as suas "rotinas de sala de aula". Os professores com mais experiência tiveram facilidade em responder a essa pergunta. Inicialmente todos disseram que usam o Plano de Ensino em suas aulas pois, o mesmo é o norteador do cronograma das aulas. Este Plano de Ensino é um documento obrigatório que cada professor tem que apresentá-lo ao Departamento de Áreas Acadêmicas em cada início de semestre.

No que se refere ao Plano de Ensino, pedimos a todos os entrevistados que nos disponibilizassem esse material para consulta. Quando fomos analisá-los, percebemos que é um plano muito "programado" e que contém dados já pré-estabelecidos, sendo um padrão da instituição, como: nome do curso, período, turno, carga horária semanal e total, carga horário de aulas práticas (10\%) e aulas teóricas (90\%), ementa, objetivo da disciplina, competências/habilidades, descrição do conteúdo (tema e sub-tema), procedimentos metodológicos e bibliografia, e que os professores somente mudavam os itens da emenda, objetivos, competências e habilidades, descrição de conteúdo (temas e sub-temas), para adequar a suas disciplinas. Já os procedimentos metodológicos que eram divididos em técnicas de ensino, 
recursos didáticos e formas de avaliação não sofreram modificação de um plano para o outro. Importa dizer que as técnicas de ensino eram compostas por aulas expositivas, aulas experimentais, plantão de dúvidas, seminários, resolução de listas de exercícios em classe e extraclasse e visitas técnicas. Já como recurso didático era previsto uso do quadro, projetor, livro didático, laboratório e artigos. E por fim, as formas de avaliação previstas era avaliação escrita e sem consulta, resolução de exercícios, apresentação de seminários e relatórios de aulas práticas. É importante destacar que todos esses itens foram verbalizados pelos professores quando os mesmos foram questionados por nós e todos eles afirmaram que os utilizam em suas aulas, ou seja, a fala deles não é diferente da prática.

Cumpre evidenciar também que o Departamento de Áreas Acadêmicas exige, por questões burocráticas de documentação, esse Plano de Ensino, mas em nenhuma fala dos professores eles apontaram que o Departamento acompanha o desempenho/execução desse plano. Conforme os docentes, "a entrega desse Plano é para cumprir a exigência da Pró-Reitoria de Ensino da Instituição", disse o professor bacharel 3. Entendemos que essa parte é de responsabilidade da área de gestão e que na prática, para os professores, é somente uma maneira de cumprir um ritual burocrático. $O$ interessante seria, inclusive para os professores mais inexperientes, que o Departamento Acadêmico (coordenação pedagógica) desse o suporte de acompanhamento da execução desse Plano de Ensino.

Ainda sobre o Plano de Ensino, um dos professores acrescentou em sua fala que a rotina de sala de aula do IFG foi uma experiência diferente para ele:

(...) as aulas do IFG são diferentes se comparadas com as aulas de cursinho, que eu tinha experiência. Lá, como resolvíamos provas de vestibulares, podíamos passar por diversos conteúdos. Aqui não. Aqui você tem que respeitar o seu Plano de Estudo e seguí-lo. Lá os exercícios eram decorebas. Aqui além de fazer exercícios, os alunos tem as aulas práticas que ajudam na fixação/ilustração dos conteúdos teóricos. (Professor Bacharel 3)

É interessante ressaltar que a maioria desses professores não fazem um plano especificado para cada aula. Eles usam o Plano de Ensino genérico. Os professores 1 e 2 disseram que já acrescentaram conteúdos além dos previstos para fins de explicação/ exemplificação. Somente o professor 1 disse que sempre faz o plano extra, mais especificado para cada aula: "Insiro muita coisa porque se for seguir somente o plano de ensino fica muito teórico".

Logo em seguida, os entrevistados foram questionados como os conteúdos das disciplinas eram ministrados por eles. Em unanimidade, os professores disseram que os conteúdos e temáticas eram expostos por aulas expositivas, uso de slides e exercícios. Além disso, indagamos esses professores bacharéis sobre como os exercícios eram aplicados. Como resposta, os professores disseram que passavam um modelo "padrão" no quadro e logo depois pediam que os alunos resolvessem conforme o modelo apresentado. Quanto à correção dos exercícios que foram mandados para serem feitos extraclasse, eles disseram que eram corrigidos no início da próxima aula.

Sempre faço assim: começo a aula explicando um conteúdo. Logo, já passo um exercício resolvido no quadro. Explico passo a passo. Depois é que os alunos começam a resolver outros exercícios bem semelhantes ao que passei no 
quadro. Isso acontece geralmente no final da aula. Aí os alunos levam os exercícios para terminar em casa. Na aula seguinte, começamos com a correção desses exercícios. É sempre assim: conteúdo, passo exercícios, os alunos respondem e eu corrijo depois (Professor Bacharel 4).

Eu finalizo minhas aulas com exercícios e a próxima aula começo já resolvendo esses exercícios e tirando as dúvidas dos alunos (Professor Bacharel 1).

Diante desse cenário, percebemos na fala dos quatro professores bacharéis essa recorrência de uma prática prescritiva, normativa, fundamentada em modelos pré-estabelecidos ao ministrar o conteúdo novo, depois apresentar um modelo de exercício, pedir que os alunos resolvam e depois passar para a parte das correções.

De acordo com Veiga (1992), esse costume ou tradição desses professores podem ser considerados como uma prática pedagógica repetitiva em que a atividade docente assume um caráter mecânico e burocrático e o professor desempenha o papel de um mero executor de um ofício.

Outro questionamento feito aos professores bacharéis foi o que eles faziam quando os alunos demonstravam dúvida na apresentação dos exercícios modelos. A maioria deles disseram que explicavam de outras maneiras.

Tem exercícios que eu tive que explicar umas três vezes diferentes para os alunos aprenderem. Também teve uma situação que eu estava explicando e eu perguntava se eles (os alunos) tinham entendido e eles disseram que não. Aí eu tive que demonstrar na prática, tipo um experimento mesmo o que o exercício estava propondo (Professor Bacharel 3).

Eu explico e pergunto se eles entenderam. Explico de novo de outra maneira. Se ainda eles não tiverem entendendo, eu tento dar exemplo, coloco número mais simples para eles entenderem. E depois, aplico na versão mais complexa (Professor Bacharel 2).

Desses depoimentos podemos perceber que mesmo que esses professores não tenham a consciência ou o conhecimento teórico de mediação e/ou estratégias de ensino, os mesmos as aplicam, mesmo que inconsciente, nas suas aulas. Veiga (1992, pág. 13) acredita que "o professor se coloca na posição de um técnico que se responsabiliza pela aplicação e difusão de instrumentos, procurando conseguir de seus alunos melhores rendimentos".

Quando foram indagados sobre como se dava a resolução desses exercícios, os professores disseram que na maioria das vezes era individual, e algumas vezes em grupos. Eis alguns posicionamentos:

Como o nosso tempo é muito curto, temos que respeitar o cronograma que é bem 'amarrado'. Então não podemos ficar perdendo tempo. Então prefiro que os alunos façam os exercícios individualmente para render minha aula (Professor Bacharel 1). 
Eu acho até bacana o trabalho em grupo. Às vezes eu peço que eles formem duplas ou trios, até para não formar as 'panelinhas' sabe? Mas gosto que eles trabalhem individualmente. Sempre acontece de um terminar primeiro que o outro. Aí para que esse aluno não fique a toa, eu peço que ele ajude os colegas que tem mais dificuldades. No final da aula, a sala está em duplas ou trios. Sempre é assim. (Professor Bacharel 2).

Uma vez ou outra eu coloco eles em grupo. Mas prefiro que resolvam as atividades sozinhos. Atividades em grupo são mais frequentes nas aulas práticas (Professor Bacharel 3).

Diante desses relatos, notamos, nas falas dos professores, que há situações em que os estudantes trabalham em grupo, ainda que os professores prefiram que os mesmos trabalhem individualmente. Contudo, percebemos que essa "possível" aprendizagem colaborativa quando desempenhada em grupo não ocorreu com propósito definido, desejável e de forma consciente pelos docentes. Percebemos que esse tipo colaborativo de aprendizagem é somente uma modalidade de trabalho, uma maneira de fazer algo diferente em sala de aula. Podemos dizer que isso não é prática pedagógica consolidada e consciente, mas sim uma prática feita aleatoriamente.

Outro ponto que perguntamos foi a respeito do surgimento de dúvidas dos alunos no momento da resolução dos exercícios e como eles as sanavam. Todos disseram que iam até a carteira do aluno ou pediam para que os mesmos se dirigissem até as suas mesas.

É de 'praxi' em todo começo de aula ter dois ou três meninos na minha mesa pedindo ajuda para resolver os exercício que ficaram pra eles resolverem em casa (Professor Bacharel 4).

É costume a gente atender o aluno na carteira dele (Professor Bacharel 2).

Quando tem muita gente com dúvida, eu peço que venham na minha mesa. Aí quando eu olho, já tem uns quatro ou cinco em cima de mim querendo ajuda para resolver os exercícios (Professor Bacharel 3).

Pela fala desses professores, evidenciamos a presença do Desenvolvimento Potencial (que compõe a ZDP) dos alunos, em que os mesmos aprendem com o auxílio do professor. Notamos, ainda, que nessas situação, o scaffolding é feito pelo professor e não pelo próprios alunos.

Ainda referente a essa questão de sanar dúvidas, dois professores disseram que quando as dúvidas na mesma questão eram recorrentes, eles iriam para o quadro e tentavam explicar para a turma toda ou escalava algum estudante para fazer a explicação para todos no quadro ou até mesmo para o próprio colega.

Quando vários alunos me chamam para ajudar na resolução da mesma questão, eu vou para o quadro e explico no quadro. Ou, eu chamo um aluno no quadro 
para que ele mesmo possa explicar. Eu percebi que isso funciona muito. Às vezes, tem aluno que resolve um determinado exercício de uma outra forma que pode facilitar o entendimento dos alunos que estão com dúvida. Acho que eles tem uma linguagem mais simples, sei lá (Professor Bacharel 1).

Nas salas sempre tem aqueles alunos que terminam as atividades primeiro. Aí, pra esses alunos não ficarem à toa, eu peço que eles ajudem outros colegas que tem mais dificuldade (Professor Bacharel 2).

Diante desse cenário podemos identificar o uso do scaffolding ou andaimes, que é uma forma de mediação os quais são vistos na teoria sociocultural vygotskyana como ferramentas psicológicas que reduzem a carga cognitiva no desempenho de uma tarefa. Para Figueiredo (2006), scaffolding é descrito como "um processo que possibilita ao aprendiz solucionar um problema, realizar uma tarefa ou atingir um objetivo que estaria além dos seus esforços, caso não tivesse a ajuda de outra pessoa" (FIGUEIREDO, 2006, p.15). As atividades de grupo ou até mesmo quando um aluno ajuda o outro na resolução de exercícios são formas de exercer o scaffolding na sala de aula. Oliveira (2010) afirma que o scaffolding por estar presente na interação, só funciona mediante a cooperação entre os indivíduos. Daí a importância das atividades colaborativas.

Outra rotina de sala de aula que esses professores foram questionados foi sobre a avaliação. Todos eles disseram que a nota dos alunos era composta pelas tarefas (exercícios em classe e extraclasse) e a prova. Sendo que dois deles (professor bacharel 1 e 3) ainda disseram que usam o seminário para compor a nota final.

Eu percebo que na indústria sempre há um trabalho em conjunto e a responsabilidade também é em conjunto. Então, como parte da nota eu uso seminário para que esses alunos entendam que o trabalho aqui dentro da sala tem que seguir o padrão que é exigido lá fora, no mercado de trabalho (Professor Bacharel 1).

$\mathrm{Na}$ nossa concepção, os seminários podem ser considerados uma prática pedagógica colaborativa pois além da interação entre os alunos, o Desenvolvimento Real (que compõe a ZDP) é ativado e isso colabora para que haja uma autonomia na construção do conhecimento.

Outro ponto que destacamos na entrevista foi o momento que perguntamos a esses professores bacharéis sobre a metodologia que eles usavam em sala de aula. Veiga (1992) menciona que a metodologia de ensino é uma expressão que teve a tendência de substituir a expressão "didática", que ganhou uma conotação pejorativa por causa do caráter formal e abstrato dos seus esquemas que não estão bem inseridos em uma verdadeira ação pedagógica. Assim, a metodologia de ensino é a parte da pedagogia que se ocupa diretamente da organização da aprendizagem dos alunos e do seu controle. Seguem os depoimentos:

Eu criei minha própria metodologia. Fui aprendendo na prática, sabe? Eu fui observando os outros professores (Professor Bacharel 1). 
Além de observar outros professores, eu pesquisei no youtube como me portar em uma sala de aula pois eu nunca tinha dado aula, e para participar do processo seletivo, umas das fases era a aula prática. Então eu vi vários vídeos que ensinava técnicas para dar aula (Professor Bacharel 4).

Eu nunca li sobre metodologia. Tudo o que eu sei hoje foi criado por mim mesmo. Eu dou aula do jeito que os meus melhores professores davam. Eu copiei eles, sabe? (Professor Bacharel 2).

Eu vi vídeos na internet com dicas para dar aula principalmente para eu dar a aula na prova didática no concurso. Eu aprendi técnicas em 3 dias. Quando tive que entrar na sala de aula pela primeira vez, essas técnicas sumiram. Tinha esquecido de verdade. Na verdade eu só usei para a prova didática. Mas agora você me perguntando, eu lembrei que eu uso algumas sim. (Professor Bacharel 3).

...E dar aula no IFG é totalmente diferente de dar aula em cursinho, que era a experiência de sala de aula que eu tinha. (...) Diferente porque aqui a gente tem que seguir um cronograma já estabelecido. Lá no cursinho a gente era mais livre. A gente só resolvia prova e os conteúdos fluíam de acordo com as dúvidas dos alunos. E lá também tinham alunos que queriam passar no vestibular. Tinham um interesse. Aqui eu já notei que tem alunos que não querem seguir uma carreira técnica na indústria, por exemplo. Só estão estudando porque é uma instituição pública e de qualidade. (Professor Bacharel 3).

"Eu vou testando com meus alunos um jeito bom de dar aula. Quando dá certo. Eu repito. Por exemplo, no começo eu tinha problemas com indisciplina na sala de aula. Os alunos não me respeitavam. Aí eu tive postura e coloquei os alunos que estavam conversando para explicar os exercícios no quadro. Acho que eles viram que eu não estava lá na frente de brincadeira. E por não serem "punidos", pararam de conversar e prestaram mais atenção nas aulas (Professor Bacharel 4).

Diante do exposto pelos professores bacharéis, fica claro que nenhum deles tiveram uma formação continuada para a docência e que os conhecimentos metodológicos descritos pelos mesmos foram assimilados por saberes da experiência, observação e prática.

Logo em seguida, para entender melhor o processo avaliativo, perguntamos aos docentes bacharéis sobre o resultado das avaliações, ou seja, das notas. O professor bacharel 3 disse que a primeira prova que ele deu os alunos tiveram muita nota baixa e ele se sentiu péssimo.

Fiquei questionando o porquê das notas baixas. Talvez foi por eu ser novato e os alunos não pegaram o meu jeito de dar aula. Ou porque minha prova estava difícil demais. Mas, cheguei a conclusão que os alunos estavam errando coisas básicas, preliminares mesmo. E eu elaborei uma prova difícil. Então, após conversas com o coordenador, eu passei mais exercícios, coloquei os meninos para praticarem mais e, claro, fiz uma prova mais acessível. As notas foram melhores. Assim como o meu relacionamento com os alunos também. Eles me conheceram melhor e eu conheci eles melhor. Agora está tudo bem (Professor Bacharel 3). 
Já o professor bacharel 1 disse que a avaliação é uma forma de verificar se o aluno aprendeu o conteúdo ministrado por ele. Ele tenta fazer uma prova com questões que "dão sentido" aos alunos e ao contexto por eles vividos, ou seja, uma prova mais contextualizada com o objeto de estudo apresentado na sala de aula. E de acordo com ele, os resultados são favoráveis.

Nessa mesma linha de pensamento Libâneo (1990) sugere aos professores que ao selecionar os conteúdos da série em que irá trabalhar, o professor precisa analisar os textos, verificar como são abordados os assuntos para enriquecê-los com sua própria contribuição e a dos alunos, comparando o que se afirma com fatos, problemas, realidades da vivência real dos alunos. Entendemos que a contextualização tem muito a ver com a motivação do aluno, por dar sentido àquilo que ele aprende, fazendo com que relacione o que está sendo ensinado com sua experiência cotidiana. Os PCNs pontuam que através da contextualização, o aluno faz uma ponte entre teoria e a prática, o que além de ser previsto na LDB e nos Parâmetros Curriculares Nacionais (BRASIL, 2012), é, também previsto nos objetivos legais dos Institutos Federais.

Todavia, salientamos que os outros três professores (professor bacharel 2, 3 e 4) ainda tem a visão que para se comprovar um aprendizado, tem que ter uma boa nota.

Se o aluno não tira nota boa, ele não aprendeu. Consequentemente nem eu e nem ele conseguiu alcançar o objetivo (Professor Bacharel 3).

A avaliação é uma forma de vermos como nossa prática de sala de aula é. Quando tem muito aluno tirando nota baixa, eu reviso a prova e tento explicar novamente o conteúdo que a maioria errou (Professor Bacharel 2).

A nota é o jeito concreto de vermos o resultado do nosso trabalho (Professor Bacharel 4).

Foi perguntado aos professores bacharéis se eles percebiam e como mediam a aprendizagem de seus alunos. Todos eles disseram que sabem perceber quando o aluno aprende ou não aprende. Três professores (bacharel 2, 3 e 4) disseram que conseguem verificar isso pela reação da face e postura dos alunos na sala de aula. O professor bacharel 2 disse: "quando eu vejo o que aluno não está participando da aula, eu vou até a carteira dele, e pergunto se ele entendeu ou não. Na maioria das vezes, o aluno não tinha entendido!" O professor bacharel 4 pontuou que: "Se ele (o aluno) tiver distraído eu faço uma pergunta para ele para que ele retome a atenção para a aula".

Eu consigo ver se meu aluno aprende ou não quando eu faço perguntas para eles durante a aula e se eles conseguem responder as minhas perguntas. Tem aqueles alunos que são mais retraídos, né? Então eu deixo esse tipo de aluno a vontade. Quando eu quero saber se ele está aprendendo o conteúdo, eu vou até a cadeira dele e vejo se os exercícios estão sendo resolvidos e pergunto se ele precisa de ajuda. (Professor Bacharel 4). 
Meus alunos aprendem mais nas aulas de exercícios porque nas aulas práticas eles acabam empolgando e desfocam do conteúdo (Professor Bacharel 3).

E para finalizar a entrevista, perguntamos a opinião desses professores Bacharéis sobre a percepção que eles tem sobre suas práticas docentes.

Hoje eu sinto que eu evolui como professor. No início eu era uma metralhadora, disparava conteúdo. Hoje não. Hoje eu consigo perceber melhor o meu aluno. Tenho interagir com ele para ter uma aula mais agradável. É um desafio para mim todos os dias (Professor Bacharel 1).

Eu percebo que eu sei o conteúdo mas quando se fala de pratica pedagógica eu não tenho conhecimento nenhum. Tem alguma receita? (Professor Bacharel 2).

Eu acho que estou delimitando minhas próprias metodologias. Entrei e não adaptei com os alunos. Mas depois peguei "mais leve" e agora estamos todos em plena harmonia. As aulas estão fluindo! (Professor Bacharel 3).

A minha aula é meio que um ritual, sabe? Eu sempre faço as mesmas coisas. Mas tenho vontade de mudar um pouco, tipo, dar uma aula diferente (Professor Bacharel 4).

Como reflexo dessas falas, é possível perceber que houve uma evolução pedagógicas, entre esses professores bacharéis, no exercício da docência. Contudo, ainda há uma carência, anseio e necessidade por parte desses professores no quesito de aprofundar e ter conhecimento sobre a relação de ensino-aprendizagem e demais elementos que fazem parte do conjunto de ações e saberes pedagógicos característicos da profissão docente.

É importante destacarmos que dada a expansão dos Institutos Federais e o expressivo aumento de professores bacharéis atuando na básica (Ensino Técnico Integrado ao Ensino Médio), algumas políticas públicas foram implantadas a fim de capacitar esses professores bacharéis. Foi promulgada a Resolução CNE/CEB no 6, de 20 de setembro de $2012^{3}$ instituiu que os mesmos deveriam passar por programas de formação pedagógica, e que o prazo para fazer essa complementação pedagógica se estenderia até 2.020 , conforme é previsto no Art. 40 :

Art. 40 A formação inicial para a docência na Educação Profissional Técnica de Nível Médio realiza-se em cursos de graduação e programas de licenciatura ou outras formas, em consonância com a legislação e com normas específicas definidas pelo Conselho Nacional de Educação.

$\S 1$ O Os sistemas de ensino devem viabilizara formação a que se refere o caput deste artigo, podendo ser organizada em cooperação com o Ministério da Educação e instituições de Educação Superior.

\footnotetext{
${ }^{3}$ Define Diretrizes Curriculares Nacionais para a Educação Profissional Técnica de Nível Médio.
} 
§ 20 Aos professores graduados, não licenciados, em efetivo exercício na profissão docente ou aprovados em concurso público, é assegurado o direito de participar ou ter reconhecidos seus saberes profissionais em processos destinados à formação pedagógica ou à certificação da experiência docente, podendo ser considerado equivalente às licenciaturas:

I -excepcionalmente, na forma de pós-graduação lato sensu, de caráter pedagógico, sendo o trabalho de conclusão de curso, preferencialmente, projeto de intervenção relativo à prática docente;

II -excepcionalmente, na forma de reconhecimento total ou parcial dos saberes profissionais de docentes, com mais de 10 (dez) anos de efetivo exercício como professores da Educação Profissional, no âmbito da Rede CERTIFIC;

III -na forma de uma segunda licenciatura, diversa da sua graduação original, a qual o habilitará ao exercício docente.

§ 30 O prazo para o cumprimento da excepcionalidade prevista nos incisos I e II do § 20 deste artigo para a formação pedagógica dos docentes em efetivo exercício da profissão, encerrar-se-á no ano de 2020 (grifos nossos).

§ 4ำ formação inicial não esgota as possibilidades de qualificação profissional e desenvolvimento dos professores da Educação Profissional Técnica de Nível Médio, cabendo aos sistemas e às instituições de ensino a organização e viabilização de ações destinadas à formação continuada de professores.

Todavia, em 2017, foi publicada a Lei $13.415 / 2017^{4}$, conhecida como a Reforma do Ensino Médio, que mais uma vez desmobiliza o processo de defesa da necessária formação específica para os docentes da Educação Profissional e Tecnológica (EPT), uma vez que ela permite a docência por professores bacharéis apenas pelo quesito do "notório saber",

Art. $61^{5}$. Consideram-se profissionais da educação escolar básica os que, nela estando em efetivo exercício e tendo sido formados em cursos reconhecidos, são:

IV - profissionais com notório saber reconhecido pelos respectivos sistemas de ensino, para ministrar conteúdos de áreas afins à sua formação ou experiência profissional, atestados por titulação específica ou prática de ensino em unidades educacionais da rede pública ou privada ou das corporações privadas em que tenham atuado, exclusivamente para atender ao inciso $\mathrm{V}$ do caput do art. 36; (Incluído pela lei no 13.415, de 2017)

Pimenta (2012) acredita que essa habilitação para profissionais com "notório saber" se apresenta como um retrocesso diante dos esforços de legitimar uma formação de professores em nível superior. Compactuamos com a mesma ideia da autora e acreditamos que se faz necessário que os profissionais tenham a valorização não apenas dos saberes da experiência,

\footnotetext{
${ }^{4}$ Que estabelece novas diretrizes e bases da educação nacional, instituindo o notório saber.

${ }^{5}$ Da Lei no 9.394, de 20 de dezembro de 1996. Estabelece as Diretrizes e Bases da Educação Nacional.
} 
como também dos saberes do conhecimento da área e dos saberes pedagógicos (PIMENTA, 2012).

Ainda registramos dois documentos que englobam a formação de professores para a educação profissional que estão em vigência. O primeiro trata-se do Plano Nacional da Educação (Lei 13.005 de 05 de junho de 2014), com vigência pelos próximos dez anos, que estabelece na estratégia 15.13 "a formação docente para a Educação Profissional se dê por cursos voltados à complementação e certificação didático-pedagógica de profissionais experientes" (BRASIL, 2014). Outro documento recente e de grande relevância para a formação de professores é a Resolução do CNE no 02, de 01 de julho de 2015. Essa Resolução define as Diretrizes Curriculares Nacionais para a Formação Continuada dos Profissionais do Magistério da Educação Básica, incluindo a modalidade de Educação Profissional.

O Art. 9o dessa referida Resolução estabelece que os cursos de formação inicial para os profissionais do magistério para a Educação Básica, em nível superior, podem ocorrer por meio de: cursos de graduação de licenciatura, curso de formação pedagógica para graduados não licenciados e cursos de segunda licenciatura. Para o nosso estudo, importa-nos remeter ao segundo meio de formação. O Art. 14 oferece maior detalhamento de como se dará tal formação:

Art. 14 Os cursos de formação pedagógica para graduados não licenciados, de caráter emergencial e provisório, ofertados a portadores de diplomas de curso superior formados em cursos relacionados à habilitação pretendida com sólida base de conhecimentos na área estudada, devem ter carga horária mínima variável de 1.000 (mil) a 1.400 (mil e quatrocentas) horas de efetivo trabalho acadêmico, dependendo da equivalência entre o curso de origem e a formação pedagógica pretendida (BRASIL, 2015, p.12).

O parágrafo 7 do Art. 14 estipula um prazo máximo de cinco anos para proceder "a avaliação do desenvolvimento dos cursos de formação pedagógica para graduados" (BRASIL, 2015. p.13).

Dessa forma, entendemos que há uma desarmonia no que tange essa temática. Há políticas públicas que foram estabelecidas para capacitar esses professores bacharéis, além de haver a predisposição, dos professores bacharéis pesquisados nesse estudo, em aprofundar a suas práticas docentes por meio de formação continuada. Todavia, notamos que na prática essa sistemática de formação continuada, prevista nas legislações supracitadas principalmente para os professores não licenciados, não consegue chegar e ser aplicada em todas as instituições que 
trabalham com a Educação Profissional, a exemplo do Câmpus pesquisado nesse estudo. No caso da Resolução do CNE no 02, de 01 de julho de 2015, como é recente e o prazo ainda não foi esgotado, até o momento não podemos chegar a nenhuma conclusão.

\section{CONSIDERAÇÕES FINAIS}

Nossa discussão objetivou conhecer as concepções de alguns professores bacharéis sobre suas práticas pedagógicas enfatizando o planejamento das aulas a partir do Plano de Ensino, metodologia e avaliação, bem como, verificar se as práticas desses docentes contemplam os elementos e conceitos de abordagem sociocultural de Vygotsky.

Podemos perceber a presença de uma prática pedagógica repetitiva apoiada no Plano de Ensino, com requisitos já pré-programados, possivelmente sem reflexão pedagógica e/ou contextualização de temáticas, contando apenas com o objetivo de cumprir o cronograma. Identificando, assim, a falta de reflexão docente e a repetição da formalidade. Constatamos, também, que a ministração dos conteúdos é por meio de aulas expositivas, usos de slides e realização de exercícios, na maioria das vezes, de maneira individual pelo estudante. Outras, em grupos.

No quesito de percepção de aprendizagem, todos os docentes bacharéis afirmam que conseguem identificar quando o aluno aprende ou não. Isso pode ser uma consequência da mediação desenvolvida por eles no relacionamento entre professor e aluno, no que se refere a preocupação desses professores em explicar o conteúdo de várias formas para facilitar a compreensão dos alunos, por exemplo. Quando à metodologia, todos eles afirmam que criaram suas próprias metodologias de atuação em sala de aula e que estão abertos para obter outras formas metodológicas de dar aula.

No que se refere a presença dos elementos/conceitos da abordagem sociocultural de Vygotsky constatamos que há situações nas aulas desses professores bacharéis que contemplam a interação social com atividades colaborativas (estudantes explicam no quadro para outros colegas ou apresentam seminários), uso dos scaffoldings, propiciando assim, a execução da ZPD do aluno. Quando os estudantes trabalham em grupos, ainda que de uma forma aleatória ou não programada, podemos perceber uma prática pedagógica desempenhada pelo professor bacharel, talvez inconsciente ou até mesmo por intuição, no âmbito da colaboração. No critério de sanar as dúvidas dos estudantes, notamos a presença do Desenvolvimento Potencial e do scaffolding, na maioria das vezes, feitos pelos professores. Talvez seja interessante os professores bacharéis conhecerem a teoria sociocultural para estimular os próprios alunos à aplicarem a execução do Desenvolvimento Potencial e do scaffolding entre eles mesmos.

Dessa forma, podemos inferir que os elementos da teoria sociocultural que foram externados por esses professores não foram executados com a finalidade de aprendizagem colaborativa, na perspectiva de apoio. Percebemos que foi algo aleatório desenvolvido por eles, sem objetivos pedagógicos preestabelecidos, baseados apenas nas suas próprias bagagens culturais. Diante dessas considerações, não podemos inferir que esses professores bacharéis não 
tem práticas pedagógicas. Não podemos condená-los, uma vez que eles não tiveram a formação para ser professor, embora estejam atuando como tal. Como, também, não podemos afirmar que o professor licenciado se orienta por práticas pedagógicas e aplica as teorias de Vygotsky em suas aulas. Talvez os licenciados, que tiveram uma formação pedagógica, estão atuando em sala de aula seguindo os mesmos critérios/práticas dos bacharéis.

Finalizamos com o seguinte questionamento: se esses professores, que não dominam a execução consciente ou programada dos processos metodológicos, soubessem as teorias pedagógicas, elas interfeririam nas aulas? Isso é proposta para refletirmos em um próximo estudo.

\section{REFERÊNCIAS}

BRASIL. (1996). Lei de Diretrizes e Bases da Educação Nacional (LDB): no 9394, de 20 de dezembro de $1996 . \quad$ Brasília: MEC. Disponível em:<http://www.planalto.gov.br/ccivil_03/leis/L9394.htm>. Acesso em: 04 de julho de 2017.

. (2007). Resolução no 1, de 27 de março de 2008. Ministério da Educação. Conselho Nacional de Educação. Define os profissionais do magistério, para efeito da aplicação do art. 22 da Lei no 11.494, que regulamenta o Fundo de Manutenção e Desenvolvimento da Educação Básica e de Valorização dos Profissianais da Educação - FUNDEB. Disponível em: < http://portal.mec.gov.br/setec/arquivos/pdf/rceb001_08.pdf>. Acesso em: 04 de julho de 2017.

. (2008). Lei 11.892. Ministério da Educação. Brasília, dezembro.

- (2012). Resolução no 6, de 20 de setembro de 2012. Ministério da Educação. Conselho Nacional de Educação. Define Diretrizes Curriculares Nacionais para a Educação Profissional Técnica de Nível Médio. Disponível em: $<$ http://portal.mec.gov.br/index.php?option=com_content\&view=article\&id=17417\&ltemid= 866>. Acesso em: 18 maio. 2018.

- (2012). Orientações Curriculares para o Ensino Médio: Linguagem código e suas tecnologias. Brasília: MEC.

. (2014). Lei 13.005, de 25 de junho de 2014. Plano Nacional de Educação - PNE. Disponível em: < http://www.planalto.gov.br/ccivil_03/_ato20112014/2014/lei/l13005.htm>. Acesso em: 18 maio. 2018.

. (2015). Resolução CNE/CP no 2, de 1ㅇ de julho de 2015 - Define as Diretrizes Curriculares Nacionais para a formação inicial em nível superior (cursos de licenciatura, cursos de formação pedagógica para graduados e cursos de segunda licenciatura) e para a formação continuada. Disponível em: < http://portal.mec.gov.br/index.php?option=com_docman\&view=download\&alias=70431- 
res-cne-cp-002-03072015-pdf\&category_slug=agosto-2017-pdf\&ltemid=30192>. Acesso em: 18 maio. 2018.

. (2017). Portal da Rede Federal de Educação Profissional, Científica e Tecnológica. Disponível em: <http://redefederal.mec.gov.br/historico.> Acesso em: 09 de maio de 2017.

$$
\text { (2017). Lei } \quad \text { no } 13.415 . \quad \text { Disponível em: }
$$
<http://www.planalto.gov.br/ccivil_03/_ato2015-2018/2017/lei/l13415.htm>. Acesso em: 18 maio. 2018.

FIGUEIREDO, F. J. Q. de. (2006). A aprendizagem colaborativa de línguas: algumas considerações conceituais e terminológicas. In: FIGUEIREDO, F. J. Q. de. (Org.). A aprendizagem colaborativa de línguas. Goiânia: Ed. da UFG. p. 11-45.

GIMENO SACRISTÁN, J. (1999). Poderes instáveis em educação. Porto Alegre: ARTMED Sul.

LIBÂNEO, J. C. Didática. (1990). Coleção Magistério: 2o Grau. São Paulo: Cortez.

LUDKE, Menga e ANDRÉ, Marli E. D. A. (1986). Pesquisa em educação: abordagens qualitativas. São Paulo: EPU, 1986.

MANFREDI. S. M. (2002). Educação Profissional no Brasil. São Paulo: Cortez.

MASETTO, M. T. ; MORAN, M. ; BEHRENS, M. (2000). Novas Tecnologias e Mediação Pedagógica. 1. ed. Campinas/SP: Papirus v. 1. 173 p.

OLIVEIRA, H. F. (2010). A construção colaborativa de conhecimento durante a interação oral de aprendizes em uma aula de LE (inglês). Revista Via Litterae, v. 2, n. 1, p. 88-101.

PERRENOUD, Philippe. (1993). Práticas pedagógicas, profissão docente e formação: perspectivas sociológicas. Lisboa : Dom Quixote.

(2000).Dez novas competências para ensinar. Porto Alegre: Artes Médicas Sul.

PIMENTA, S. G. (2012). Pedagogia universitária: caminhos para a formação de professores. São Paulo: Corte.

SOUZA, F.C.S.; NASCIMENTO, V.S.O. (2013). Bacharéis Professores: um perfil docente em expansão na Rede Federal de Educação Profissional e Tecnológica. In: MOURA, D.H (Org.) Produção do conhecimento, Políticas Públicas e Formação Docente em Educação Profissional. Campinas, SP Mercado de Letras. p. 409-434

VEIGA, I.P.A. (1992). A prática pedagógica do professor de Didática. 2.Ed. Campinas: Papirus.

VYGOTSKY, L. S. (2007). Interação entre aprendizado e desenvolvimento. In: VYGOTSKY, L. S. A formação social da mente. São Paulo: Martins Fontes. 